\title{
HYDRAULIC HEAVE - DESIGN CHARTS AND DESIGN FORMULA FOR THE REQUIRED EMBEDDED LENGTH
}

\author{
Benjamin AULBACH ${ }^{\mathrm{a}}$, Martin ZIEGLER ${ }^{\mathrm{a}, \mathrm{b}}$ \\ aZAI Ziegler und Aulbach Ingenieurgesellschaft mbH, Schloss-Rahe-Str. 15, 52072 Aachen, Germany \\ ${ }^{b}$ Geotechnical Engineering, RWTH Aachen University, Mies-van-der-Rohe-Str. 1, \\ 52074 Aachen, Germany
}

Received 05 January 2014; accepted 04 May 2014

\begin{abstract}
For the determination of the required embedded length for the safety against hydraulic heave several approximate solutions exist. However, most of these solutions do not take into account the geometrical boundary conditions such as width B and length $\mathrm{L}$ of the excavation as well as the thickness of the aquifer S. Thus, values obtained by such simplified approximate solutions can easily lead to either uneconomical or unsafe design. For this reason investigations on the safety against hydraulic heave have been carried out at the Chair of Geotechnical Engineering at RWTH Aachen University. Based on the results of numerous calculations dimensionless design charts have been generated. With the help of these design charts the required embedded length $\mathrm{T}$ can be determined quite easily taking into account the difference of the ground water level $\mathrm{H}$, the Thickness of the aquifer $\mathrm{S}$, the geometrical dimensions $\mathrm{B}$ and $\mathrm{L}$ of the excavation and the unit weight of submerged soil $\gamma^{\prime}$. In addition to these design charts a formula has been developed. By use of this design formula the required embedded length can directly be determined taking into account the before mentioned boundary conditions.
\end{abstract}

Keywords: hydraulic heave, failure, design, charts, formula, groundwater flow, excavation.

\section{Introduction}

For the determination of the required embedded length for the safety against hydraulic heave several approximate solutions exist. These however produce very varying results, as shown in Figure 1.

Comparing the approximate solutions, the resulting embedded lengths for the current example vary by a factor of up to about eight. The numerical quantity of the factor depends on whether the individual solution considers the geometrical boundary conditions such as width $B$ and length $L$ of the excavation. Neglecting the geometry unsafe results can be obtained for narrow excavations.

For this reason, systematic investigations on the safety against hydraulic heave have been carried out

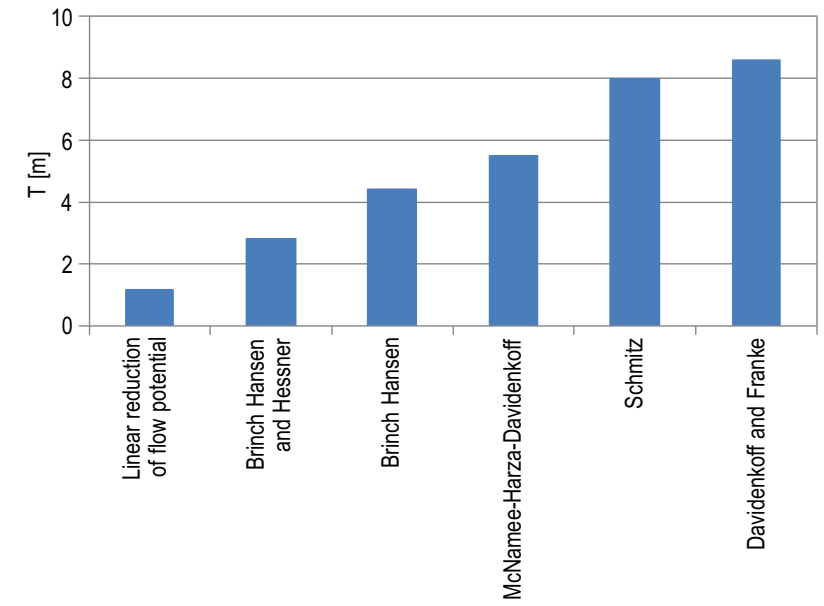

Fig. 1. Embedded length T obtained by several approximate solutions for an excavation with a width of $\mathrm{B}=10 \mathrm{~m}$ and a difference of water level of $\mathrm{H}=10 \mathrm{~m}$

Corresponding author:

B. Aulbach E-mail: info@zai-ingenieure.de 
at the Chair of Geotechnical Engineering at RWTH Aachen University. Based on the results of numerous calculations dimensionless design charts have been generated. With the help of these design charts the required embedded length $\mathrm{T}$ can be determined quite easily taking into account the difference of the ground water level $\mathrm{H}$, the geometrical dimensions of the excavation $\mathrm{B}$ and $\mathrm{L}$, the thickness of the aquifer $\mathrm{S}$ and the unit weight of submerged soil $\gamma$ '. In addition to the design charts a formula has been developed allowing the straight determination of the required embedded length under considering the before mentioned boundary conditions.

\section{Design according to Eurocode 7}

In Europe the verification of resistance to failure by hydraulic heave is set by Eurocode 7: Geotechnical design - Part 1: General Rules (EN 1997-1, German version: DIN EN 1997-1, 2009). The verification of resistance within the so called limit state HYD can be done in two different ways. On the one hand by comparing the design values of the total pore water pressure $\mathrm{u}_{\mathrm{dst} ; \mathrm{d}}$ with the total vertical stress $s_{s t b ; d}$ and on the other hand by comparison of the design values of the seepage force $S_{\text {dst; }}$ with the submerged weight $G_{\text {stb;d }}^{\text {, of the }}$ same considered soil column (see Eqns (1) and (2)).

$$
\begin{gathered}
\mathrm{u}_{\mathrm{dst} ; \mathrm{d}} \leq \sigma_{\mathrm{stb;d}} \\
\mathrm{S}_{\mathrm{dst} ; \mathrm{d}} \leq \mathrm{G}_{\mathrm{stb} ; \mathrm{d}}^{\prime}
\end{gathered}
$$

According to the German National Annex to EN 1997-1 (DIN EN 1997-1/NA 2010) and the supplementary national rules established in DIN 1054:2010 the second way was chosen for the investigations presented in this paper. The partial factor for the destabilizing actions $\gamma_{\mathrm{G} ; \mathrm{dst}}$ within EN 1997-1 is renamed in DIN 1054 by the partial factor $\gamma_{H}$ (Eqn (3)).

$$
\mathrm{S}_{\mathrm{dst} ; \mathrm{k}} \cdot \gamma_{\mathrm{H}} \leq \mathrm{G}_{s \mathrm{tb} ; \mathrm{k}}^{\prime} \cdot \gamma_{\mathrm{G} ; \mathrm{stb}} \text {. }
$$

One special feature of DIN 1054 is the differentiation between favourable and unfavourable soil. Gravel, sandy gravel, dense sand with grain sizes bigger than $0.2 \mathrm{~mm}$ and stiff clayey soil are defined as favourable soil whereas loose sand, fine sand, silt and soft cohesive soil are defined as unfavourable soils.

As hydraulic heave typically occurs in excavations, mostly the design situation BS-T (transient situations) with $\gamma_{\mathrm{H}}=1.30$ for favourable and $\gamma_{\mathrm{H}}=1.60$ for unfavourable soil becomes relevant. The partial factor for permanent favourable actions amounts to $\gamma_{\mathrm{G} ; \mathrm{stb}}=0.95$ for all design situations (cf. Table 1).

As mentioned before the verification of resistance against hydraulic heave has to be done by comparison of the favourable and unfavourable actions acting in the same soil column. EN 1997-1 universally specifies that for every relevant soil column safety shall be verified, whereas DIN 1054 recommends that in case of a vertical seepage flow in front of a retaining wall a body of soil should be investigated which's width generally is half of the embedded length. Figure 2 shows the socalled Terzaghi-body.

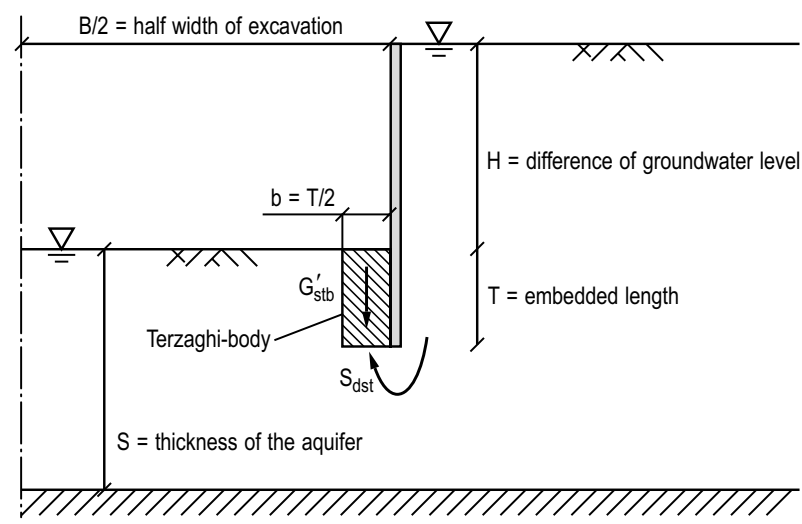

Fig. 2. Two-dimensional system including the Terzaghi-body

Within the research projects preliminary investigations on the relevant soil column had been carried out which confirmed that the Terzaghi-body is a well working approximation (cf. Aulbach 2013; Aulbach, Ziegler 2014). For this reason, the Terzaghi-body was chosen for the following investigations.

\section{Investigations and design charts for plane conditions}

In a first step investigations for homogeneous, isotropic soil under plane conditions had been carried out. For this, four different unit weights of submerged soil $\gamma^{\prime}=9 \div 12 \mathrm{kN} / \mathrm{m}^{3}$ were investigated and in each case it was distinguished between favourable and unfavourable soil by setting the corresponding partial safety-factor (Table 1).

Based on the results of these investigations design charts have been generated in which all geometrical variables are normalised by the difference of the groundwater level H (cf. Fig. 1). Hence, dimensionless design charts are obtained which take into account the geometric conditions like the width of the excavation 
Table 1. Partial factors of safety according to DIN 1054

\begin{tabular}{|l|c|c|c|c|}
\hline \multicolumn{1}{|c|}{ Action } & Symbol & BS-P & BS-T & BS-A \\
\hline $\begin{array}{l}\text { Soil weight, } \\
\text { stabilizing }\end{array}$ & $\gamma_{\mathrm{G}, \mathrm{stb}}$ & 0.95 & 0.95 & 0.95 \\
\hline $\begin{array}{l}\text { Seepage force, } \\
\text { favourable soil }\end{array}$ & $\gamma_{\mathrm{H}}$ & 1.35 & 1.30 & 1.20 \\
\hline $\begin{array}{l}\text { Seepage force, } \\
\text { unfavourable soil }\end{array}$ & $\gamma_{\mathrm{H}}$ & 1.80 & 1.60 & 1.35 \\
\hline
\end{tabular}

$\mathrm{B}$ and the thickness of the aquifer S. Finally eight design charts have been generated which can be found in Aulbach (2013).

The design charts for a unit weight of submerged soil of $\gamma^{\prime}=11 \mathrm{kN} / \mathrm{m}^{3}$ and for favourable soil conditions is exemplified below (Fig. 3).

On the vertical axis the required embedded length related to the difference of the groundwater level $\mathrm{T} / \mathrm{H}$ is plotted against the width of the excavation related to the difference of the groundwater level $\mathrm{B} / \mathrm{H}$ on the horizontal axis. Furthermore, the different curves take into account the actual thickness of the aquifer $\mathrm{S} / \mathrm{H}$.

The design chart shows quite clearly that the width of the excavation has an enormous influence on the safety. By decreasing the width B the required embedded length $\mathrm{T}$ increases disproportionately as for narrow conditions the hydraulic potential for most part is reduced inside the excavation for reasons of continuity. Furthermore, the influence of the aquifer becomes obvious. The higher the thickness of the

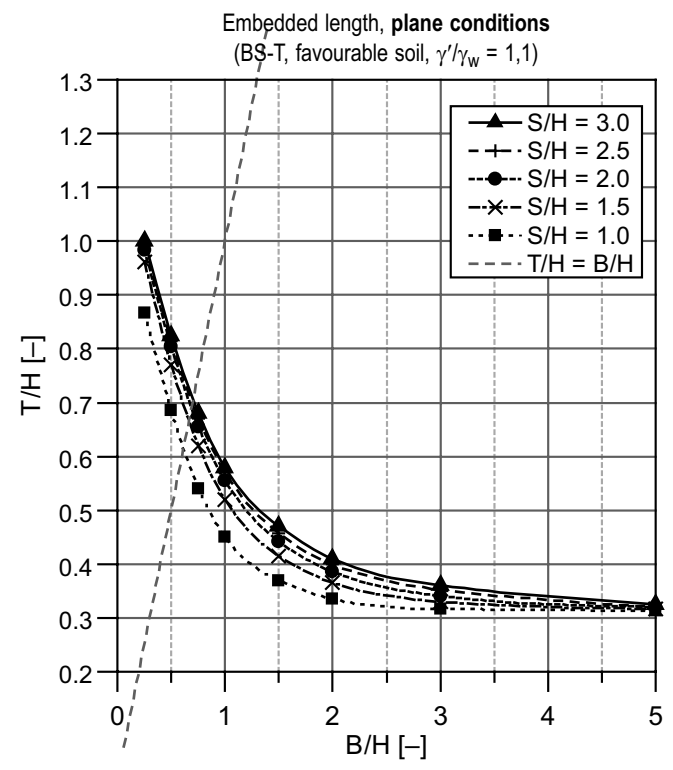

Fig. 3. Design chart for homogenous, isotropic and favourable soil under plane conditions aquifer $\mathrm{S}$ the higher is the required embedded length. This also results from continuity as for thin aquifers more of the hydraulic potential is reduced within the reduced sectional area below the retaining wall.

\section{Investigations and design charts for three-dimensional conditions}

In addition, extensive investigations for three-dimensional conditions have been carried out. For this purpose the length $\mathrm{L}$ of the excavation was varied leading to different width-length-ratios $\mathrm{B} / \mathrm{L}$ of the excavation (Fig. 4).

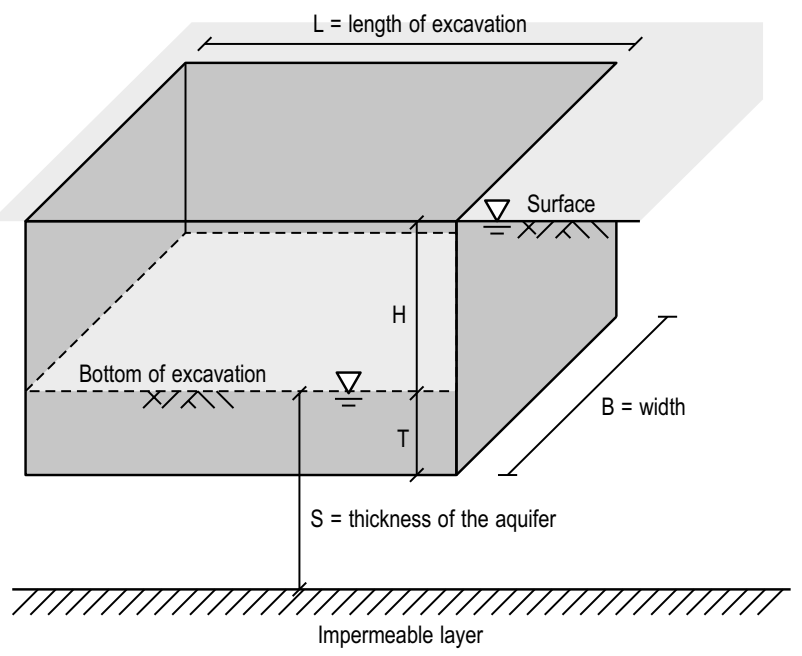

Fig. 4. System sketch for three-dimensional conditions

The ratio was varied from $\mathrm{B} / \mathrm{L}=1.0$ for square to $\mathrm{B} / \mathrm{L}=0.5$ for rectangular to $\mathrm{B} / \mathrm{L}=0.3$ for elongated excavations. Furthermore, it was distinguished between the corner and the midpoints of the front and the long side of the excavations. Hence, for every combination of width of the excavation and thickness of the aquifer three embedded lengths have been determined for rectangular excavations $(\mathrm{B} / \mathrm{L}<1.0)$ and two embedded lengths for square excavations respectively.

As the number of necessary calculations increases for three dimensional conditions a software module had been developed together with the Institute of Hydraulic Engineering and Water Resources Management of RWTH Aachen University. This module has automatized the iterative determination of the required embedded length in parts.

Based on the results, dimensionless design charts also for the considered three-dimensional conditions have been generated. The design charts for a unit weight of submerged soil of $\gamma^{\prime}=11 \mathrm{kN} / \mathrm{m}^{3}$, favourable 
soil conditions and a width-length-ratio of $\mathrm{B} / \mathrm{L}=0.5$ are exemplified below for the corner (Fig. 5), the front side (Fig. 6) and the long side (Fig. 7).

The design charts for $\mathrm{B} / \mathrm{L}=0.3$ and $\mathrm{B} / \mathrm{L}=1.0$ and other unit weights of the submerged soil can be found in Aulbach (2013).

The results of the three-dimensional calculations clarify the great influence of the width of an excavation once more. Furthermore, the comparison of the design charts shows that in the corner area a higher embedded length is required compared to the sides and even

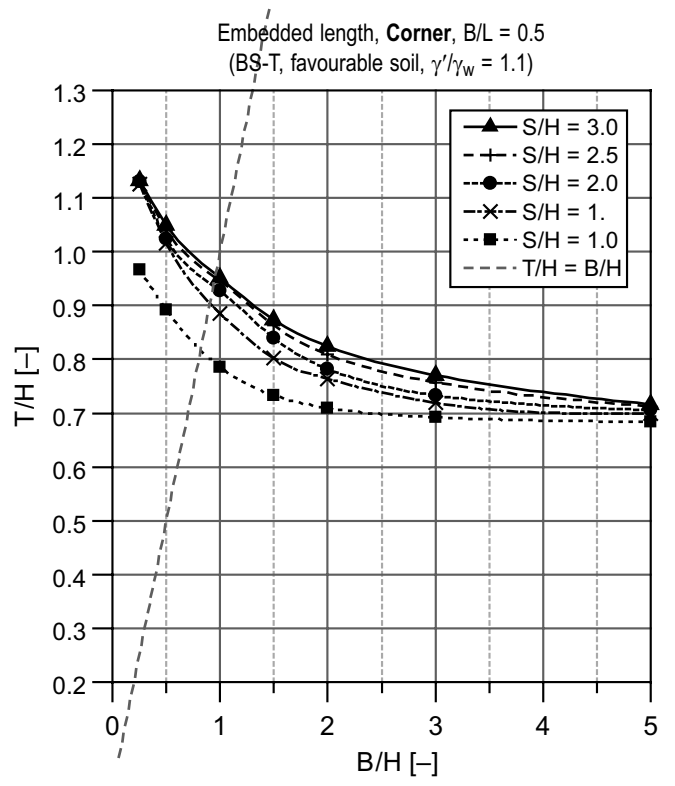

Fig. 5. Design chart for the corner area in homogenous, isotropic and favourable soil under three-dimensional conditions

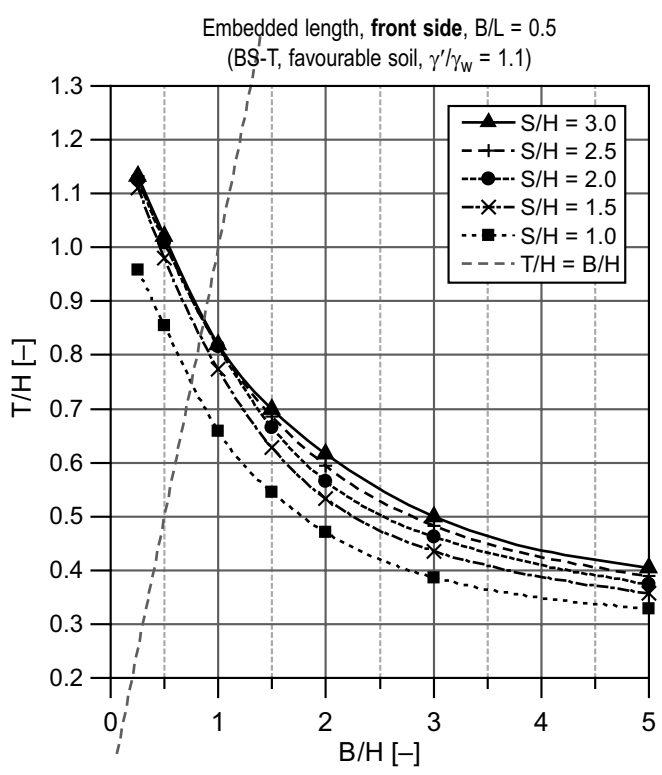

Fig. 6. Design chart for the short side in homogenous, isotropic and favourable soil under three-dimensional conditions

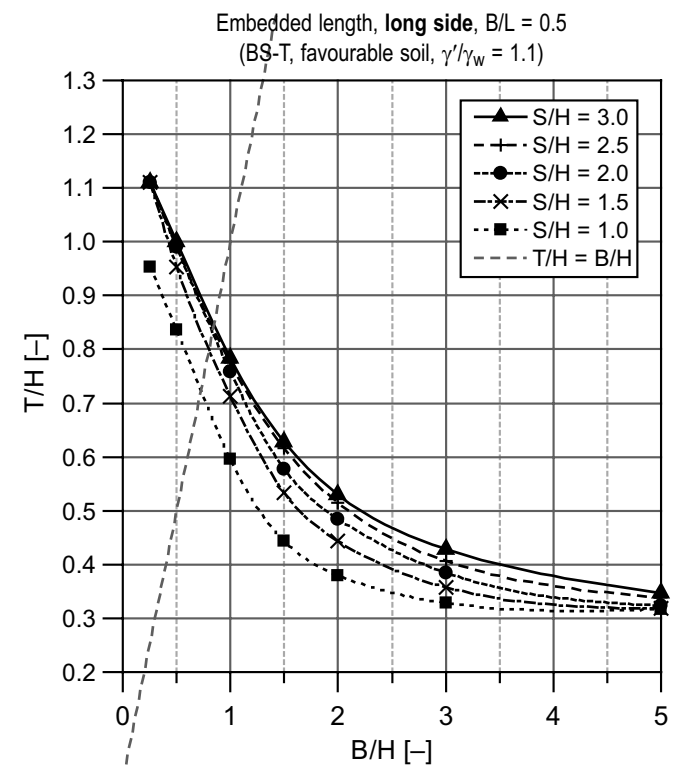

Fig. 7. Design chart for the long side in homogenous, isotropic and favourable soil under three-dimensional conditions

more compared to the plane conditions (cf. Fig. 3). However, for very narrow excavations the differences decrease as under those conditions the main part of the hydraulic potential is reduced inside the excavation for reasons of continuity.

In order to consider four different unit weights of the submerged soil already eight design-charts were necessary for homogenous, isotropic soil under plane conditions considering favourable and unfavourable soil. For three-dimensional conditions, even 64 design charts had to be generated to distinguish between the corner and the sides and to consider different values of B/L (cf. Aulbach 2013).

\section{Formula for planar conditions}

Each of the design charts represents an instrument, with which the required embedded length can be determined quickly and with great accuracy for the relevant situation. However, the great number of charts seems rather unwieldy. Therefore, the next step was to develop progressively an approximate design formula yielding the same results with sufficient accuracy.

The required embedded length $\mathrm{T}$ related to the difference of the water level $\mathrm{H}$ for

- any width B and

- any thickness of the aquifer $\mathrm{S}$,

- plane conditions,

- homogeneous, isotropic soil,

- which can be categorised as favourable and 
- which has a submerged unit weight of $\gamma^{\prime}=11 \mathrm{kN} / \mathrm{m}^{3}$

can be determined with the formula:

$\frac{\mathrm{T}}{\mathrm{H}}=0.32+(1.244-0.32) \cdot e^{\left(\frac{-\frac{\mathrm{B}}{\mathrm{H}}}{0.541+0.395 \cdot\left(1-e^{\left(1-\frac{\mathrm{S}}{\mathrm{H}}\right)}\right)}\right)}$.

Extensive details of the derivation of this formula can be found in Aulbach (2013).

\section{Formula for three-dimensional conditions}

Finally, the previous formula was extended and combined with other formulae to enable its application for three-dimensional conditions, any unit weight of submerged soil and different safety levels (cf. Aulbach 2013; Aulbach, Ziegler 2013).

This results in the overall formula shown in Figure 8 , which includes a design constant Be to compensate for deviations of the original formulae from the exact results of the FE calculations or design charts so that the results always lie on the safe side. Applying the factor Be the average deviation from the FE results for favourable soil conditions is $\Delta \mathrm{T} / \mathrm{H} \approx 9 \%$, and for unfavourable ground $\Delta \mathrm{T} / \mathrm{H} \approx 12.5 \%$. Without a design constant, the average deviations are only $\Delta \mathrm{T} / \mathrm{H} \approx 2.5 \%$ and $\Delta \mathrm{T} / \mathrm{H} \approx 6 \%$ respectively, but with change of sign.

It should be stressed at this point that the present investigations are only valid for non-cohesive soils. Cohesive soils can suffer quite different failure mechanisms under some circumstances, so that the design using only the formula is impermissible. In addition, if non-cohesive soil is categorised as unfavourable, completive investigations should be obligatory to exclude untypical failure types such as internal erosion.

\section{Further investigations}

Finally, it should be mentioned that for anisotropic or stratified soil conditions the required embedded length might increase as a larger part of the hydraulic potential has to be reduced inside the excavation. For this reason, investigations considering these soil conditions have been carried out and design charts and approximate formulae respectively have been developed.

The required embedded length in anisotropic and stratified soil is influenced by the ratio of the permeabilities. However, as the determination of permeabil- ity is one of the most difficult tasks in geotechnical engineering, the parameters can often only imprecisely be determined or only roughly estimated. Therefore, an additional sensitivity analysis should be carried out with respect to the range of permeability of the considered soils.

Further details on anisotropic and stratified soils can be found in Aulbach (2013).

\section{Summary and conclusions}

Extensive numerical flow calculations were performed to develop numerous dimensionless design charts. These can be used to directly read off the required embedded length for the safety against hydraulic heave depending on the decisive boundary conditions e.g. difference of the water level, thickness of the aquifer, width and length of the excavation and location in the excavation (corner, front, long side) and also depending on the soil conditions.

In addition, a formula was stepwise derived which enables the determination of the required embedded length in a simple way depending on the before mentioned variables. The deviations between the embedded lengths calculated with the formula and those from the numerical calculations are generally very small.

The presented formula (Fig. 8) can be directly established in structural design programmes to determine the embedded length with respect to the hydraulic as well as to the structural requirements. This should avoid in future the iteration of the required embedded length, alternating between flow analysis and structural design programmes. This was formerly only possible using greatly simplified design formulae, which however do not consider the geometrical boundary conditions, which can lead to unsafe results for narrow excavations.

\section{Acknowledgement}

The development of the formula is based on results and data, which were mostly produced as part of two research projects supported by the Deutschen Institut für Bautechnik (DIBt). We wish to thank the DIBt and the members of the support group.

Thanks are also due to the company Wayss \& Freytag Ingenieurbau AG, who were involved in the first research project and also supported both projects financially. 


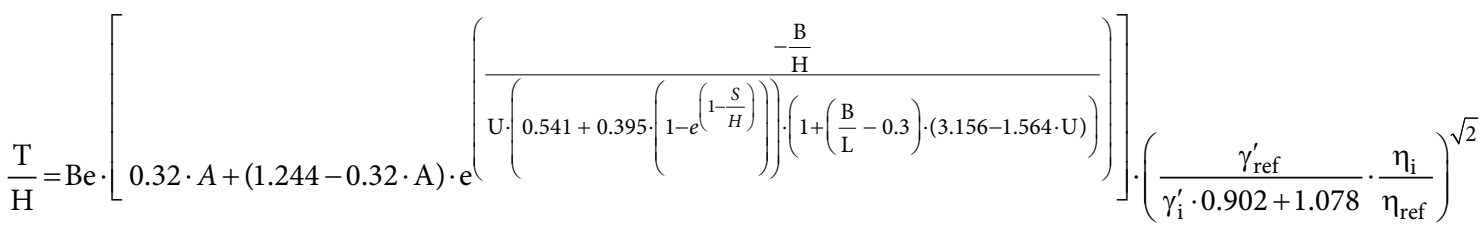

With:

Be design factor

A spatial flow factor

$\mathrm{U}$ surroundings factor

$L$ length of construction pit

$B$ width of construction pit

$\mathrm{H}$ difference of groundwater level

$S$ thickness of aquifer

$\gamma_{\text {ref }}^{\prime}$ reference value of unity weight $=11 \mathrm{kN} / \mathrm{m}^{3}$

$\gamma_{i}^{\prime}$ unity weight

$\eta_{\text {ref }}$ reference value of global safety $=1.368=1.30 / 0.95$

$\eta_{\mathrm{i}}$ required global safety
DIN $1054(2010) \rightarrow B e=1.065$

\begin{tabular}{|l|c|c|}
\hline Factors & $\mathrm{A}$ & $\mathrm{U}$ \\
\hline Plane conditions & 1.00 & 1.00 \\
\hline Long side & 1.00 & 1.32 \\
\hline Front side & 1.04 & 1.99 \\
\hline Corner & 2.08 & 1.69 \\
\hline
\end{tabular}

Range of application

$\mathrm{T} / \mathrm{H}<0,75 \cdot \mathrm{S} / \mathrm{H}$

$S / H \geq 1.0$

$B / L \geq 0.3$

Fig. 8. Design formula for homogenous, isotropic and favourable soil under three-dimensional conditions

Further thanks are due to the Emschergenossenschaft, the Hamburg Port Authority AÖR and the ICG Düsseldorf $\mathrm{GmbH}$ \& Co. KG for financial support. Special thanks to the Institut für Wasserbau und Wasserwirtschaft of RWTH Aachen University for their collaboration with the development of the interface software module.

\section{References}

Aulbach, B. 2013: Hydraulischer Grundbruch - Zur erforderlichen Einbindetiefe bei Baugruben in nichtbindigem Baugrund: PhD thesis. Aachen: RWTH Aachen University.

Aulbach, B.; Ziegler, M. 2013: Simplified design of excavation support and shafts for safety against hydraulic heave, Geomechanics and Tunnelling 6(4): 362-374.
Aulbach, B.; Ziegler, M. 2014: Versagensform und Nachweisformat beim hydraulischen Grundbruch - Plädoyer für den Terzaghi-Körper, Geotechnik 37(Heft 1): 6-18.

DIN EN 1997-1:2009-09: Eurocode 7: Entwurf, Berechnung und Bemessung in der Geotechnik - Teil 1: Allgemeine Regeln. Berlin: Beuth Verlag, 2009.

DIN EN 1997-1/NA:2010-12: Nationaler Anhang - National festgelegte Parameter - Eurocode 7: Entwurf, Berechnung und Bemessung in der Geotechnik - Teil 1: Allgemeine Regeln. Berlin: Beuth Verlag, 2010.

DIN 1054:2010-12: Baugrund - Sicherheitsnachweise im Erdund Grundbau - Ergänzende Regelungen zu DIN EN 1997-1. Berlin: Beuth Verlag, 2010.

Benjamin AULBACH. He is the Chief Executive Officer at ZAI Ziegler und Aulbach Ingenieurgesellschaft mbH. In 2013, he defended his $\mathrm{PhD}$ thesis "Hydraulic heave: the required embedded length for construction pits in non-cohesive soil". He was Scientific Assistant at the Chair of Geotechnical Engineering at RWTH Aachen University (2007-2013); Studies of Civil Engineering at the Technical University of Darmstadt (1999-2007).

Martin ZIEGLER. He is the Professor at the Chair of Geotechnical Engineering, Head of the Institute of Foundation Engineering, Soil Mechanics, Rock Mechanics and Waterways Construction at RWTH Aachen University and Chief Executive Officer at ZAI Ziegler und Aulbach Ingenieurgesellschaft mbH. In 1998-2000 he was a Managing Director of Philipp Holzmann Planungsgesellschaft mbH in Neu-Isenburg, in charge of: business administration, Department of Infrastructure, Department for Project- and Claim Management. In 1987-1998: Philipp Holzmann AG; in 1987 he wrote his PhD thesis "Calculation of the displacement dependent soil pressure in sand"; 1980-1987: Scientific Assistant at the Institute for Soil Mechanics and Rock Mechanics at the University of Karlsruhe; 1979 -1980: Postgraduate Studies of Soil Mechanics at the Institute for Soil Mechanics and Rock Mechanics at the University of Karlsruhe; 1973-1979 Studies of civil engineering at the University of Karlsruhe. 